
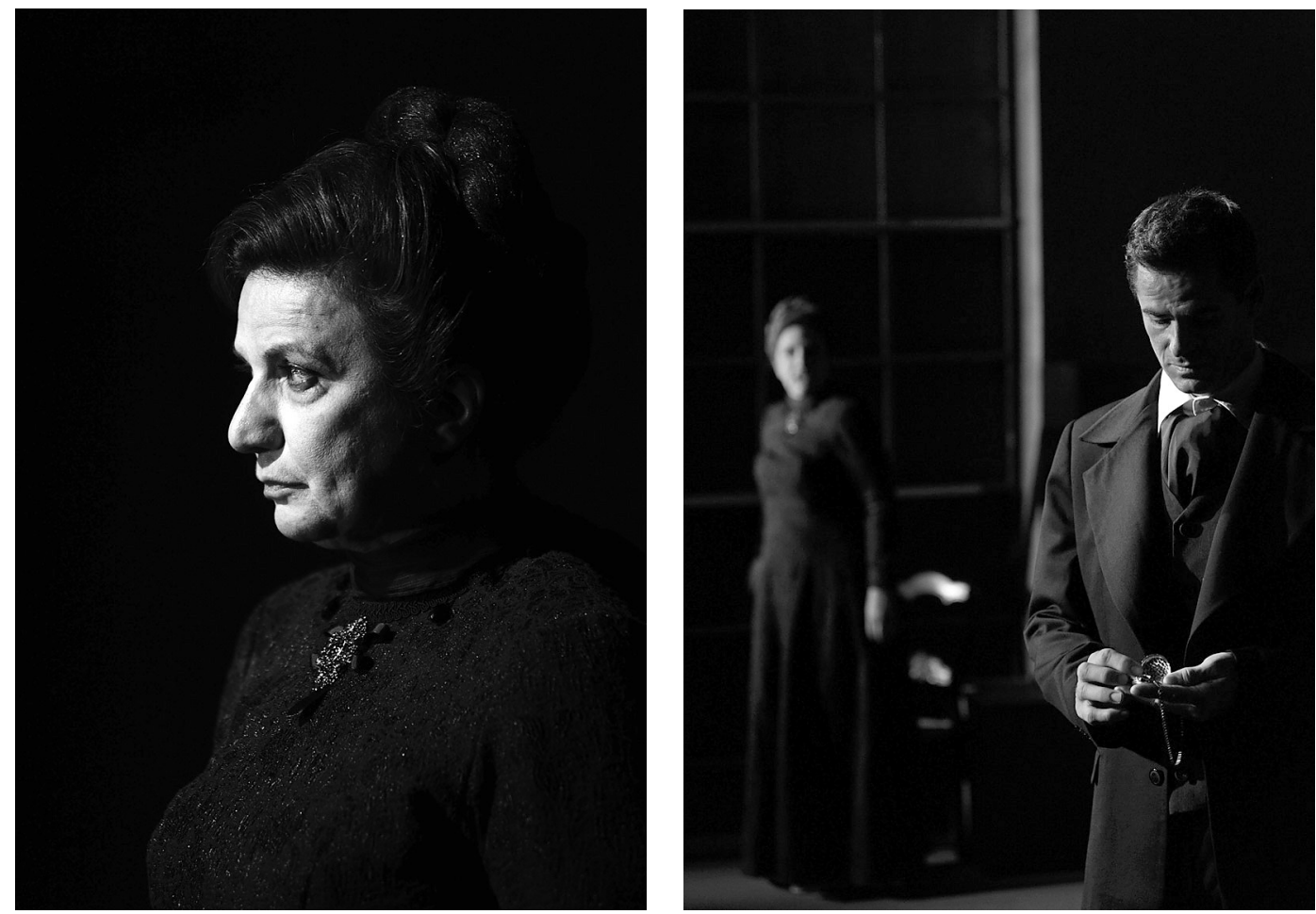

$<>$

O pelicano,

de August Strindberg,

enc. Rogério de Carvalho, Companhia de Teatro de Almada, 2013

(<Teresa Gafeira $>$ Teresa Gafeira, Pedro Lima), fot. Jorge Gonçalves.

\title{
Um festival movido a pedais
}

\section{Rodrigo Francisco}

No final da década de 90, um homem de teatro galego, Adolfo Simón, referia-se ao Festival de Almada como "um transatlântico movido a pedais". Nessa época, ainda sedeado no pequeno teatro municipal, o Festival tinha já encetado várias parcerias com alguns dos principais teatros lisboetas. Parcerias essas que tornaram possivel apresentar pela primeira vez em Portugal espectáculos de criadores como Peter Brook, Giorgio Strehler, Benno Besson, Roger Planchon, Patrice Chéreau - entre muitos outros.

No final dos anos 90 - época na qual o financiamento público à Companhia de Teatro de Almada conheceu um importante avanço -, o Festival de Almada era já um evento de dimensão internacional. Mas ainda assim nunca perdeu o pé - ou melhor, os pedais. 0 seu fundador e homem do leme -Joaquim Benite - nunca abandonou o gosto de pedalar serenamente nas águas que não poucas vezes Ihe foram adversas. E creio que foi justamente essa forma artesanal de estar no teatro e na vida, essa capacidade de não se deixar deslumbrar pelo sucesso e não se desviar do rumo traçado, que em grande medida justifica o prémio que temos o gosto de hoje vir receber. De 1984 (ano da sua fundação) a esta parte, o Festival de Almada evoluiu e transformou-se bastante, mas nunca perdeu o fito dos valores que estiveram na sua origem: o amor pela Arte, a instilação da inquietude, o respeito pelo público. 0 mesmo público que aqui está tão bem representado: várias gerações de pessoas que se

mobilizaram para percorrer $600 \mathrm{~km}$. de ida e volta até ao Porto, porque sentem que, de alguma forma, este prémio também é delas. Creio que por aqui também passa a razão pela qual fomos premiados.

Mas, trinta anos passados, os valores que subjazeram à criação do Festival de Almada encontram-se ameaçados. Querem tirar-nos os pedais. 0 discurso professado pelas forças que actualmente predominam na Europa procuram a todo o custo enxertar os valores economicistas na matriz cultural. Por cá, em consonância, a tutela encomenda estudos que defendem que a cultura seja sustentável do ponto de vista económico. Mas não é. Ou melhor: ainda não é.

Basta estudar os regulamentos do programa de fundos europeus para a cultura, o projecto Europa Criativa 20142020, para destrinçar as intenções por detrás do discurso de que a Cultura pode ter um papel importante na criação de riqueza. Sim, na verdade pode. Ao longo da História da Humanidade os artistas não têm feito outra coisa senão criar coisas boas e belas: gerar riqueza. Mas essa riqueza não é mensurável pelas bitolas economicistas. Ou haverá alguém nesta sala capaz de dizer-me quanto custam Os Lusiadas?

Os fundos europeus em questão destinam-se a financiar "indústrias criativas": no total, cerca de 455 milhões de euros serão distribuídos em seis anos. E neste nebuloso e um tanto paradoxal conceito de "indústrias criativas" (como se pudesse haver fábricas de pintar Mirós em série, ou de compor em barda Quintas Sinfonias), nesta amálgama difusa, cabem festivais cervejeiros, cabem produtores de jogos de vídeo, e cabem festivais de teatro como o nosso. Assim se vê como o discurso sobre a
Rodrigo Francisco é Director Artístico da Companhia de Teatro de Almada e do Festival de Teatro de Almada 


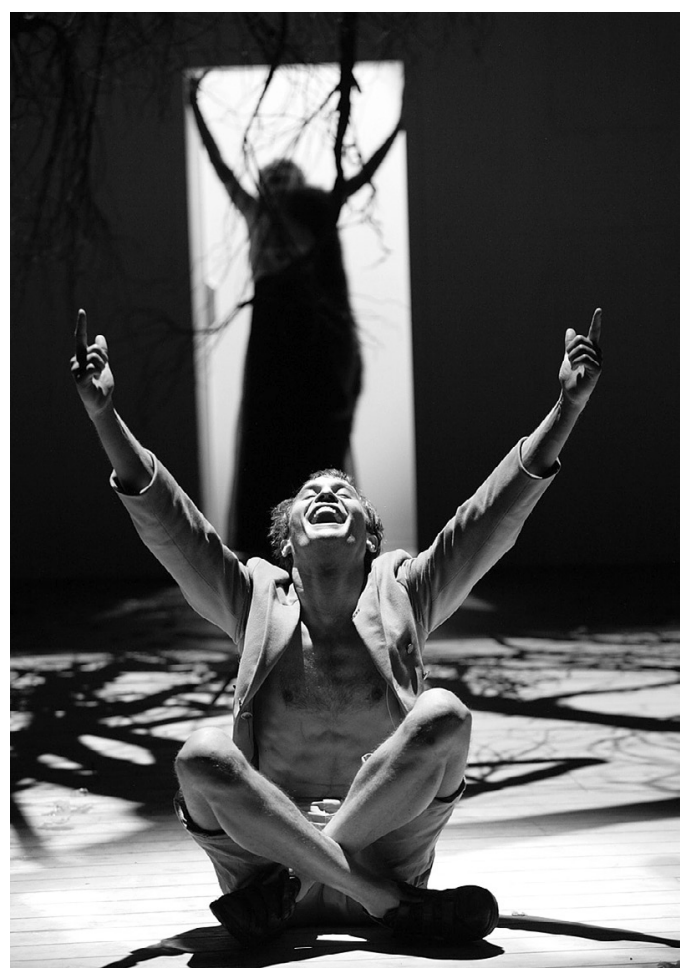

Victor ou as criancas a

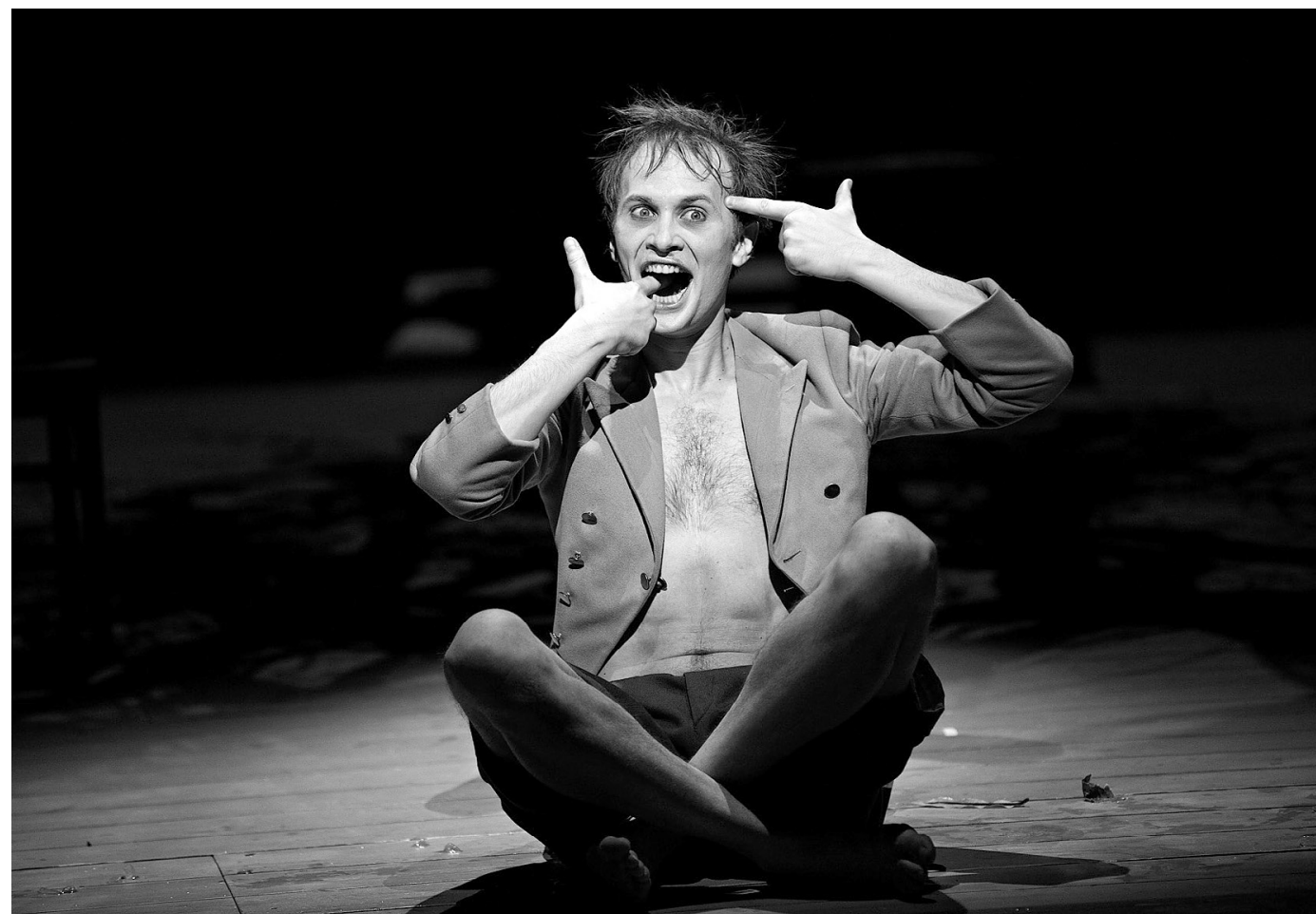

necessidade da sustentabilidade económica da Cultura procura, encapotadamente, servir de alavanca para desviar o financiamento das artes... para a Nintendo.

E eu acho que entendo esta mudança: a uma certa ideologia convirá que, em vez de se frequentar teatros, espaços de debate e discussão de ideias por excelência, se fique em casa a jogar no computador. Para essa gente, entretenimento também é cultura, porque os jogos de vídeo (ou os eventos/festarola) vendem bem, geram dinheiro. Falamos-Ihes em fruição artística e eles respondem-nos com pilim.
Pois bem, foi justamente por oposição a estas forças, que procuram transformar a Arte numa mercadoria, que se fundou o Festival de Almada. É o facto de ao longo dos últimos trinta anos termos combatido esta tendência que fez, creio, com que fôssemos premiados pela Associação Portuguesa de Críticos de Teatro. Pelo que nos toca, continuaremos a pedalar. 